\title{
3. CONVENCIONES CONSTITUCIONALES Y REGLAS DE CORRECCIÓN CONSTITUCIONAL
}

(I)

\author{
PEDRO JOSÉ GONZÁLEZ TREVIJANO \\ Profesor de Derecho Constitucional \\ Facultad de Derecho \\ Universidad Complutense
}


PRIMERA PARTE.-LAS CONVENCIONES CONSTITUCIONALES.I. INTRODUCCION. II. IMPORTANCIA, CONCEPTO Y CARACTERISTICAS DE LAS NORMAS CONVENCIONALES CONSTITUCIONALES. III. NATURALEZA DE LAS CONVENCIONES CONSTITUCIONALES: FORMULACIONES DOCTRINALES MAS DESTACADAS. 1. Aportaciones clásicas en la doctrina brifánica y germánica. 2. Otras aportaciones clásicas en el Derecho constitucional británico. 3. Las aportaciones doctrinales más sobresalientes en el Derecho continental. 4. Posición que se defiende. IV.-ALgunos EJEMPLOS DE CONVENCIONES CONSTITUCIONALES EN EL DERECHO CONTINENTAL COMO INSTRUMENTO DE MODIFICACIONES CONSTITUCIONALES. 


\title{
3. CONVENCIONES CONSTITUCIONALES Y REGLAS DE CORRECCIÓN CONSTITUCIONAL
}

\author{
POR \\ PEDRO JOSÉ GONZÁLEZ TREVIJANO \\ Profesor de Derecho Constitucional \\ Facultad de Derecho. \\ Universidad Complutense

\section{PRIMERA PARTE \\ LAS CONVENCIONES CONSTITUCIONALES}

\section{INTRODUCCIÓN}

Junto a las estrictamente hablando costumbres constitucionales, e incluso en ocasiones confundiéndolas con aquéllas, se habla en el Derecho constitucional de normas convencionales de la constitución conventions of the constitution. Si bien dicha categoria normativa es una creación del Derecho constitucional británico, y fuertemente arraigada, asimismo, en el constitucionalismo americano, sin embargo, han sido de un tiempo a esta parte estudiadas y analizadas en el Derecho continental europeo, y preferentemente en la doctrina italiana, al menos por lo que respecta especialmente a los últimos años.

El objeto del presente trabajo es, en primer lugar, conceptualizar y caracterizar dichas normas convencionales no solamente en el Derecho británico, donde como hemos señalado, hallan su máxima expresión e importancia, sino también en el ámbito de los países de Derecho continental, donde cada día se destaca de mayor modo su trascendencia y relieve en el proceso de la misma "dinámica constitucional».

En segundo lugar, nos detendremos en recoger las aportaciones doctrinales más sobresalientes acerca de la naturaleza y fundamentación de las reglas convencionales, destacando los planteamientos más significados, no sólo en Gran Bretaña y Estados Unidos, sino asimismo en la doctrina francesa, alemana, italiana y española, preferentemente.

En tercer término, analizaremos el papel que en la práctica desempeñan las convenciones constitucionales como una de las manifestaciones más distinguidas de las denominadas mutaciones constitucionales. Final- 
mente, la trascendencia tanto del derecho consuetudinario como del derecho convencional, como manifestaciones del Derecho constitucional no escrito - si bien es cierto que puede haber normas consuetudinarias y reglas convencionales fijadas por escrito-integrando, interpretando, y hasta contradiciendo lo preceptuado en los textos constitucionales formales, incluso en las constituciones más rígidas.

\section{IMPORTANCIA, CONCEPTO Y CARACTERISTICAS DE LAS NORMAS CONVENCIONALES CONSTITUCIONALES}

Como punto de partida podemos definir las convenciones constitucionales como aquellas reglas de conducta que por acuerdo o pacto expreso o tácito de los diferentes operadores políticos y órganos constitucionales, disciplinan el ejercicio concreto de sus poderes y facultades, y que tradicionalmente despliegan sus efectos normativos en aquellos ámbitos que carecen de regulación en los textos constitucionales, o en todo caso, en los supuestos en que aun habiendo una disciplina normativa al respecto, ésta no es más que de naturaleza discrecional, perfilando de este modo el ejercicio concreto de dichos poderes y atribuciones'.

Así, sirven como instrumento válido para el mejor cumplimiento de los diferentes fines para los que se asignaron las referidas facultades, 0 de modo general, para un correcto y adecuado desarrollo de la acción política ${ }^{2}$.

Se trata, por lo tanto, de reglas o prácticas de naturaleza varia, que son consideradas y sentidas como obligatorias y vinculantes para los sujetos políticos que las establecen y cumplen, y ello, a pesar de no ser derecho legislado, lo que hace en la práctica no sean accionables según el campo en el que se desarrollen, ante los diferentes órganos jurisdiccionales o ante las propias Cámaras Parlamentarias. Serían de esto modo, reglas no legislativas, es decir, normas que no hallarian su origen en los modos de producción normativa «legalmente» reconocidos.

Nos parece a este respecto, acertada la definición de CRISAFULLI, quien entiende por convenciones constitucionales, aquellos acuerdos tácitos (eventualmente expresos) entre los titulares de los órganos políticos para resolver los problemas y dificultades que de hecho se producen en la aplicación concreta de las normas y disposiciones constitucionales. Su función consistiría de esta manera, en integrar, delimitar y circunscribir el ámbito de discrecionalidad en el ejercicio de los poderes en que estas

T. Maftines, Diritto Costituzionale, Giuffré, 2." ed., Milán, 1981, pág. 91.

2 F. Pergolesi, Diritto costituzionale, Cedam, 2. ${ }^{a}$ reimp. de la $15 .^{a}$ ed., Padua, 1972, pág. 350 . 
últimas se fundan o despliegan. Dichos acuerdos darian lugar al establecimiento de un precepto generalizado, que los diferentes operadores y sujetos políticos se obligan a cumplir y respetar, pero sin que pueda ser alegado su cumplimiento, ya sea directa o indirectamente, ante los órganos judiciales ${ }^{3}$.

La propia denominación británica de conventions of the constitution, afirmará FERRACCIU recogiendo el parecer de parte de la doctrina alemana al respecto, implica la representación de una formulación contractual consciente, cuya fuerza normativa hallaría su fundamento en el mismo acuerdo tácito de los órganos supremos del Estado ${ }^{4}$, y ello aun reconociendo que muchas de dichas reglas puedan encontrar su origen en la mera praxis politica y constitucional.

Pero cualquiera que sea el concreto significado que se atribuye a las normas convencionales constitucionales, habría quizás también que hacer hincapié en la terminología utilizada por la doctrina para describir dicho complejo de reglas y normas. Al respecto, la primera impresión que se tiene, es la de la ausencia de una terminología bien concreta, de la inexistencia de una expresión de carácter univoca, de modo parecido a como tendremos ocasión de ver cuando nos ocupemos más adelante de la naturaleza juridica de dichas normas, aspecto sobre el cual tampoco la doctrina se ha manifestado unánime e inequívocamente.

Asi, se ha afirmado recientemente la pluralidad de significantes o denominaciones de dichas categorias normativas. En este sentido, se ha hablado de custom, de «moralidad política de la Constitución»; de «sistema completo de moralidad política, como código de preceptos que sirven de guia a los hombres públicos»; de usage dentro del cual se hallarian incluidos tanto las convenciones constitucionales como otros usos; de pratiques constitutionnelles y pratiques non écrit; en la doctrina germánica se habla de Gewonhwitsrecht, incluso como expresión más generalizada de las ungeschriebnes Verfassungsrecht; algunos las confunden con las denominadas normas de corretezza costituzionale, e incluso para otros no habria diferencia entre convenciones y costumbres constitucionales ${ }^{5}$.

En todo caso, y dejando precisiones terminológicas al margen, lo que se presenta como indiscutible, es la trascendencia que dichas normas desarrollan en el ámbito de los poderes y relaciones constitucionales y políticas en ordenamientos jurídicos bien diferentes.

Así, y en primer lugar, cabe destacar el papel preminente que desempeñan en el sistema británico de las fuentes de la constitución, pues

3. Crisafulli, Lezioni di Diritto Costituzionale, T. II, Cedam, Padua, 1978, pág. 152.

A. Ferracciu, La consuetudine costituzionale, Fratelli Bocca, Turín, 1921, pág. 41.

5 Denominaciones todas estas recogidas en A. Elvira PERALES, Las convenciones constitucionales, págs. 125 y ss. 
no hay que olvidar que la Constitución inglesa no es el resultado exclusivo de las disposiciones constitucionales escritas, sino de un complejo heterogeneo de disposiciones de derecho legal, consuetudinario y convencional.

Es bien sabido en este sentido que las relaciones entre la Corona, el Gobierno y el Parlamento se hallan poco disciplinadas por el derecho legal constitucional, dándose la paradoja de que mientras la estructura jurídica formal de la articulación de los poderes se establece en manos del Monarca, por el contrario y en la realidad, el centro de gravedad del actual sistema político se encontraba en el Parlamento, y concretamente en la Cámara de los Comunes ${ }^{6}$. En dicho ámbito las convenciones constitucionales han favorecido la inserción en el Derecho constitucional de antiguas prácticas y usos, del en una época no muy alejada todopoderoso common law, dando lugar a una manifiesta evolución del anterior orden políticoconstitucional, que en un primer momento se traslada del Rey al Parlamento (de modo particular acabara triunfando la Cámara Baja sobre la Cámara de los Lores), para configurarse en un segundo momento, como una forma de gobierno donde la piedra angular es el propio Gabinete.

En este sentido, y a título meramente descriptivo se pueden señalar las siguientes categorias: en primer término, aquellas reglas convencionales que restringen los poderes del soberano (asi, la que le obligaría a escoger como Primer Ministro al jefe del partido más influyente en la Cámara de los Comunes, a nombrar a los ministros que aquél designa; a seguir las orientaciones políticas establecidas por el Gabinete; a sancionar las leyes aprobadas por el Parlamento y a convocarlo anualmente); en segundo lugar, aquellas normas convencionales que favorecen el funcionamiento del mismo Gobierno de Gabinete, señalando la libertad de acción del Ministerio y su carácter colegiado frente a la responsabilidad en que pudiera incurrir frente a la Cámara; finalmente, no se podrían olvidar aquellas convenciones que en el pasado presidian las relaciones entre el Reino Unido y los diferentes países de la Conmonwealth ${ }^{7}$.

La trascendencia institucional de las mismas, es pues, como se puede apreciar muy grande. Por ejemplo, y conforme al Derecho constitucional escrito, lós ministros no son más que "comisarios» del monarca $y$, por lo tanto revocables unilateral y libremente por aquél, y los barcos y navíos de guerra y los edificios públicos serían asimismo propiedad exclusiva de éste. No obstante, si la realidad jurídico politica es bien diferente a lo que se deduciria de una exclusiva observación de los textos y documentos escritos, ello se debe en gran parte al papel desempeñado por las convenciones constitucionales ${ }^{8}$.

- G. Treves, «Convenzioni costituzionale», en Enciclopedia del Diritto, T.X. Giuffre, Milán, 1962, pág. 524.

7 lbidem, págs. 524.525.

- J.L. LaCRuz Berdejo, Elementos de Derecho Civil, Bosch, Barcelona, 1974, pág. 55. 
En cuanto a las características más sobresalientes de las conventions of the constitution, se pueden quizás resaltar las siguientes:

En primer lugar, y dejando todavía al margen el problema de su juridicidad del que nos ocuparemos más adelante, lo que si se puede destacar, pensamos, es que se trata de verdaderas normas y no de simples usos o prácticas políticas, y, por lo tanto revestidas de la nota de obligatoriedad.

En segundo término, y amén de la imposibilidad de poder exigir su exacto y debido cumplimiento ante los órganos judiciales ordinarios, al menos por lo que respecta al Derecho constitucional británico, las convenciones se caracterizan por la falta de formalismo, es decir, por la ausencia de obligada forma jurídica alguna, lo que no supone como se ha señalado con anterioridad, que las partes y sujetos políticos que adecuen su comportamiento a lo prescrito en ellas, no lo hagan con la finalidad de satisfacer $y$ dar cumplimiento a una conducta exigida, obligada y debida ${ }^{9}$.

De esta suerte y si bien la ausencia de formalidad es la nota común a la mayoria de las convenciones constitucionales, sin embargo, hay algunas que revisten elevado carácter solemne y formal. Tal sería, por ejemplo, el caso de las convenciones que disciplinan el discurso de la Corona en Inglaterra.

- En tercer lugar, las convenciones suelen hallar su origen en particulares y concretas circunstancias sociales y políticas, fijando una obligación a cumplir o respetar, aunque éstas hayan encontrado su propio nacimiento en la misma voluntad de los sujetos llamados a cumplirlas y respetarlas. Aparecen, bien a causa del desarrollo de una cierta práctica a la que va indisolublemente unido un adecuado sentimiento obligatorio, o bien de un pacto o acuerdo expreso, en cuyo caso, la existencia de un solo comportamiento fija la norma de conducta a exigir, siendo ordinario en dichos casos, el que revistan el carácter de escritas.

De este modo, y a diferencia de las normas consuetudinarias, las convenciones constitucionales suelen expresarse tanto por lo que respecta a su nacimiento como a su pérdida de vigencia o desuso, de una manera al menos relativamente precisa.

En cuarto lugar, se suele presentar la justificación de dichas normas convencionales en la ordenación de la Constitución formal a las variables, contingentes y modificables circunstancias de la vida político constitucional de cualquier estructura socio-política o político jurídica. Como señala acer-

9 G. Rescigno, Le convenzioni costituzionali, Cedam, Padua, 1972, pág. 109. 
tadamente MARSHALL, “la existencia de una convención es una cuestión histórica y sociológicas"

En quinto lugar y por lo que respecta a la desaparición o extinción de ciertas normas convencionales hasta entonces vigentes en el ámbito constitucional y político de un determinado país, dicho fenómeno puede deberse a los más múltiples y variados fenómenos. Así, la extinción puede producirse, amén de que puedan transformarse en otro tipo de normas, como tendremos ocasión de señalar, por la mutación o cambio de las peculiares circunstancias que habian dado lugar a su nacimiento; por voluntad expresa o tácita de los sujetos, o al menos, de algunos de ellos; por el establecimiento de una nueva norma convencional o de otro tipo; en fin, quizás, también, por el propio desuso de aquéllas.

Finalmente, las convenciones constitucionales vienen a responder a dos principios, que en parte parecen contradictorios: de un lado, se manifiestan como hemos tenido ocasión de señalar, como un complejo normativo que trata de adaptar y plegar la regulación constitucional del Estado a las exigencias y nuevas vicisitudes de los tiempos. Las convenciones se presentan por lo tanto, con la finalidad de adaptar y aclimatar el viejo derecho a las nuevas necesidades de la vida político constitucional, evitando el siempre traumático procedimiento de reforma formal constitucional; de otra parte sin embargo y paradójicamente, las convenciones constitucionales llevan implícita la nota de tradición y conservadurismo, como característica no sólo natural sino esencial de dichas normas.

En todo caso, las reglas convencionales han de encuadrarse dentro del respeto y aceptación de las líneas maestras del ordenamiento jurídico constitucional, así como de los principios constitucionales que informan y caracterizan a aquél. Por ello, nos parecen acertadas las construcciones doctrinales que ven en las convenciones de la constitución, no sólo un campo abonado para el posterior desarrollo de las instituciones constitucionales, sino así mismo de la propia salvaguardia de la "Constitución": "en relación con esta función, el respeto hacia las convenciones es signo del que se siente hacia la propia Constitución, mostrando el acatamiento hacia el pacto constitucional y un equilibrio político, que serán completos si coinciden con el sentir de la opinión pública"".

De lo reseñado se deduce inmediatamente, la enorme importancia que las normas convencionales pueden desplegar en los diferentes sistemas jurídicos, y especialmente en el Derecho británico y en el Derecho constitucional consuetudinario. Como hemos tenido ocasión de destacar, las normas convencionales han ido aportando en Inglaterra antiguas disposiciones del common law, dando lugar a una adaptación de las normas constitucionales a la nueva situación social y política heredada del devenir

10 G. Marshall, Constitutional conventions, Clarendon Press, Oxford, 1984, pág. 11.

"Elvira Perales, ob. cit., pág. 134. 
de los tiempos. De esta manera, y aun permaneciendo sustancialmente inalterables los textos y documentos constitucionales escritos, el efectivo poder político ha ido sucediéndose, como se ha señalado, del Monarca al Parlamento (en un primer momento, destacando la Cámara de los Lores, para con el transcurso del tiempo ir perdiendo fuerza y autoridad en detrimento de la Cámara de los Comunes), y finalmente, de éste a la institución del Gabinete.

Destacada importancia desarrollan asimismo en Estados Unidos, que heredaría, al menos en parte, el sistema británico de los modos de producción jurídica, pero reconociendo los límites que al desarrollo y consolidación de las normas convencionales supone el carácter escrito y rígido de la Constitución de 1787. Así, y a través de las reglas convencionales, la constitución escrita ha ido siendo no solamente completada sino también modificada y alterada, haciendo plenamente vigente la afirmación de MUNRO para quien «el hábito es para el individuo, lo que el uso para el Estadom ${ }^{12}$.

Más adelante tendremos ocasión de referirnos a la posibilidad de exportar dichas normas, nacidas en los paises del common law, a los esquemas de los sistemas. jurídicos continentales, y en particular por lo que se refiere al Derecho constitucional italiano.

En cualquier caso, la trascendencia de las convenciones constitucionales en la Constitución británica sería de tal grado, dice GARCíA PELAYO, que en vano se tratarian de encontrar en los documentos constitucionales escritos, aspectos e instituciones tan fundamentales de la vida constitucional británica, como el Primer Ministro, el Gabinete, la oposición de su Majestad, la convocatoria anual del Parlamento, la responsabilidad política, la disolución de la Cámara a requerimiento del Primer Ministro, el nombramiento de éste entre los miembros de la mayoría parlamentaria, la nulidad del veto real, etc... ${ }^{13}$. Así, se podrá decir, que las relaciones entre el Monarca, el Gobierno y el Parlamento no han variado sustancialmente desde las consecuencias jurídicas fijadas por la Revolución de 1688, debiéndose a las normas convencionales reseñadas la profunda transformación constitucional y política acaecida en Inglaterra desde entonces a nuestros dias.

Por ello y tratando de esquematizar la variada fenomenologia convencional, nos parece interesante la distinción de GREAVES, quien diferencia tres grandes clases o tipos de reglas convencionales: a) aquellas convenciones «que son preceptos directivos generales o reglas de convivencia para asegurar una armonía adecuada entre el Parlamento y el Eje-

12 W.R. Munro, The Government of the United States, Mac.Millan Co., Nueva York, 1947 pág. 72.

3 M. Garcia Pelayo, Derecho constitucional comparado, Manuales de la Revista de Occidente, 6." ed., Madrid, 1981, pág. 286. 
cutivo a la luz del principio de la soberanía parlamentaria» (por ejemplo, la responsabilidad del Gabinete); b) las convenciones «que tienden a asegurar la armonia entre la acción legislativa y gubernamental, por un lado, y el veredicto del electorado o de la opinión pública, por el otro" (así, no puede aprobarse una legislación que afecte a materias básicas sin reclamar la opinión del electorado); c) finalmente, «las destinadas al mejor funcionamiento de una institución particular" (tal es el caso de la intervención de los Lores jueces, cuando la Cámara de los Lores actúa como tribunal) ${ }^{14}$.

Con éxito sintetizador, KEITH ha señalado que las normas convencionales - al menos las más básicas e importantes - "sirven para resolver la larga lucha entre la Corona y el pueblo de forma que se asegure que el poder discrecional de la Corona se ejercerá de acuerdo con los deseos de la Cámara de los Comunes, como poder hegemónico del Estado, y, además, de acuerdo, en último lugar, con los deseos del electorado»" ${ }^{15}$.

La tipología de las diferentes normas convencionales es sin embargo muy variada, dependiendo de la perspectiva o enfoque doctrinal que de las mismas se haga. Asi, se habla por algún sector doctrinal de convenciones que establecen deberes, y de convenciones que conceden derechos, entre los que suele estar la facultad del monarca de negarse en determinadas circunstancias a la solicitud del.Primer Ministro de disolver el Parlamento ${ }^{16}$.

HARTLEY y GRIFFITH, distinguirán según la trascendencia de las materias objeto de regulación convencional, de un lado, aquellas que podríamos calificar de esencialísimas y que caracterizarian las instituciones, poderes y relaciones más básicas de la estructura constitucional, y que con el transcurso del tiempo se han consolidado como verdaderos principios constitucionales; de otro lado, aquéllas de menor relevancia y que vienen a completar más que otra cosa lo preceptuado en el derecho legislado, regulando, de este modo las relaciones entre los distintos sujetos políticos. Tales son los supuestos más representativos, y aquellas que suelen recibir específico estudio en el ámbito del Derecho constitucional ${ }^{17}$.

Es clásica, asimismo, la diferenciación de WADE and PHILLIPS, entre convenciones descriptivas, que serian aquellas basadas en la observación de lo que en realidad acontece, y convenciones prescriptivas, que hacen referencia a lo que ha de acontecer, basadas en parte en la observación pero también en los principios constitucionales" ${ }^{18}$.

\footnotetext{
18 Ecs. WADE, and G.G. PHILIPS, Constitutional and Administrative Law, Longman, Londres, 1982, pág. 17.
} 1981, pág. 6.

Ibidem, pág. 287

A.B. KEITH, Constittutional Law, Stevens and s., Londres, 1946, pág. 6.

MARSHALL, ob. cit., págs. 7-8.

T.C. HARTLEY y J.A.G. GRIFFITH, Gobernment and Law, Weindenfel y Nicolson, Londres, 
Además, y por su relación con el derecho legislado, se habla de convenciones praeter legem, que completan e integran las normas constitucionales escritas, secundum legem que interpretan y concretan el contenido de éstas, y contra legem, o en oposición a lo preceptuado en el Derecho constitucional escrito.

En el Derecho' continental y en partircular en la doctrina italiana, RESCIGNO partiendo de las posibles relaciones entre el derecho legal y las normas convencionales, diferencia los siguientes supuestos: a) aquéllos que vienen a sustituir el contenido de las disposiciones legales, dejando reducidas estas últimas a simples elementos de forma; $b$ ) las que delimitan el contenido de las reglas legales, concretando las posibles interpretaciones de aquéllas; $c$ ) las normas convencionales que presuponen la disciplina legal de una materia u objeto, pero sin que se incorporen a las reglas legales de que se trate un significado político posterior ${ }^{19}$.

Menor importancia tienen aquellas clasificaciones que atienden a los órganos fundamentales del Estado, o las que disciplinan las relaciones de los órganos accesorios de éste, o en fin, a las que normativizan las instituciones y relaciones básicas, o por el contrario, las que reglamentan instituciones menos destacadas y relaciones más sencillas.

Lo importante de todas ellas es en todo caso, y clasificaciones al margen, la función de adaptación de las viejas normas y formulaciones concretas a las nuevas transformaciones históricas, y la posibilidad de hacer real la vigencia de los textos constitucionales responden así, «a la nota de flexibilidad y empirismo..., y vienen a ser la vía de integración de nuevas situaciones en el esquema tradicional de las instituciones inglesas, dándoles a éstas un nuevo sentido; gracias a ellas se verifica la superación de la antinomia entre el presente y el pasado ${ }^{20}$.

Ahora bien, ¿cómo se reconoce la existencia de una convención constitucional? A dichos efectos se han señalado los siguientes criterios orientativos: en primer lugar, la existencia de una serie de precedentes; en segundo lugar, dichos comportamientos y precedentes deben hallarse asistidos del conocimiento de su obligatoriedad; finalmente, ha de existir una cierta razón que justifique satisfactoriamente el establecimiento de la referida regla convencional ${ }^{25}$.

Sin embargo, la determinación de dichos elementos no se realiza siempre con criterios muy precisos: asi, de una parte se reconoce que también de un solo comportamiento puede nacer el precedente que de lugar al establecimiento de la norma convencional; de otra parte, que no todos

19 Rescigno, ob. cit., págs. 23-25.

20 Garcia Pelayo, ob. cit., pág. 287.

${ }_{21} G$. ZABREBELSKY, "La formazione del Governo nelle prime quattro legislature repubblicane», en Rivista Trimestrale di Diritto Pubblico, n. ${ }^{3}$, Milán, 1968, pág. 808. 
los precedentes se hallan forjados de fuerza vinculante, como good precedents, y que harian referencia lógicamente a la propia ratio de la regla convencional.

En última instancia, y tanto en cualquiera de los supuestos referidos, la piedra angular que condiciona tanto la existencia como la obligatoriedad de las convenciones constitucionales es la opinión pública. La importancia de esta última, dirá ZAGREBELSKY, ha de entenderse en sentido amplio como la concepción general de la estructura política de la sociedad, adquiriendo en el campo de las reglas convencionales una destacada importancia. $Y$ ello es así, porque de una parte constituye el impulso necesario para la creación de nuevas convenciones, y de otra, se manifiesta como garantía, aunque no necesariamente exclusiva de su existencia y observancia ${ }^{22}$.

\section{NATURALEZA DE LAS CONVENCIONES CONSTITUCIONALES: FORMULACIONES DOCTRINALES MÁS DESTACADAS}

Es tradicional cuando se realiza un estudio sobre las convenciones constitucionales, tratar de dar una solución doctrinal a la problemática de - la naturaleza jurídica de dichas reglas, problema éste muy debatido no sólo en el ámbito de la doctrina inglesa, sino también entre los autores de Derecho continental que posteriormente fueron con el transcurso del tiempo ocupándose paulatinamente del tema.

A tal efecto, vamos a comenzar por recoger las aportaciones doctrinales más destacadas en el Derecho constitucional británico, para pasar luego a examinar las construcciones más sobresalientes, al respecto, en el Derecho alemán e italiano, países en donde la recepción de dicha categoría normativa fue más feliz y compartida.

\section{Aportaciones clásicas en la doctrina británica y germánica}

La primera de las aportaciones doctrinales a la problemática de la naturaleza jurídica de las convenciones constitucionales, es como no podría ser de otro modo, la de Dicey.

Partirá DICEY de la afirmación de que las normas convencionales a diferencia de las leyes constiłucionales son la expresión de un conjunto de

Ibidem. Una seleccionada bibliografia, al respecto, en las notas 7 y 8 . 
prácticas y máximas que representan un cuerpo que podriamos denominar de moral constitucional o política.

Dichas reglas que formarian parte de la moral constitucional más actual, no pueden ser consideradas derecho legal, por no ser susceptibles de recibir sanción judicial, siendo su campo de acción principalmente el ejercicio de los poderes discrecionales de la Corona o los poderes o privilegios de las Cámaras. Lo trascendente sería que dichas reglas convencionales podrian ser calificadas de cuasi-obligatorias, siendo respetadas, como lo son, la mayor parte de las disposiciones legislativas, y hallando su fuerza obligatoria en la misma fuerza de la ley o derecho legislado, que indirectamente resultarían violados al producirse la infracción de aquéllas.

Se diferenciará por DICEY, entre reglas convencionales precisas, como por ejemplo, las que imponen a un ministro la obligación de dimitir cuando no goce de la confianza de la Cámàra, y otras reglas convencionales menos concretas, más vagas o inciertas, como podrán ser las que regulan las relaciones personales de la Corona y la conducta del Gobierno ${ }^{23}$.

La aportación doctrinal referida'puede ser objeto, no obstante, de las siguientes matizaciones: de una parte, tiene el mérito indiscutible de haber analizado esta compleja y sorprendente fuente del constitucionalismo británico, señalándose su carácter obligatorio, que en cierta manera se equipara al de las propias y verdaderas leyes constitucionales, analizando el carácter de indeterminación y movilidad de las mismas ${ }^{24}$; no nos parece convincente, en cambio, la afirmación de que queden fuera del mundo jurídico, por el simple hecho de no poder ser accionadas ante los tribunales y órganos jurisdiccionales ${ }^{25}$, como consecuencia de una visión del Derecho estrictamente imperativista y típica del mundo anglosajón, en el que el enforcement judicial se considera esencial para la calificación o no de las normas como jurídicas ${ }^{26}$.

La segunda de las grandes aportaciones doctrinales es la de HATSCHEK, quien comenzaria por afirmar, que si bien es cierto como sostuvo al respecto DICEY, que la mayor parte de dichas convenciones y reglas convencionales no serían más que el simple resultado de reglas de la praxis política, sin embargo, habria una parte de aquellas que, por el contrario, si podrían considerarse como auténticas normas jurídicas.

La determinación de los límites entre las simples máximas políticas y las reglas jurídicas de carácter convencional, podría hallarse en la constatación de la juridicidad de todas aquellas que hicieran ilusoria una cierta

23 A.V. DiCEY, Law of the Constitution, Londres, 1885, pág. 23.

24 Así, ferracciu, ob. cit., pág. 51.

25 Ibidem.

26 Al respecto, ZabREBELSKY, ob. cit., pág. 807 , nota 4. 
norma del reglamento parlamentario, de las leyes emanadas del Parlamento o de alguna de sus instituciones. Por ello, y en contra de las argumentaciones de DICEY, se afirmará, de una parte, la imposibilidad para todas las reglas convencionales de hallar una norma jurídica ya preexistente a la que acogerse, y de otra, la consideración de normas jurídicas de ciertas normas convencionales como podrian ser aquellas cuya inobservancia conduciría a un conflicto con reglas o instituciones establecidas en los reglamentos parlamentarios.

Asimismo, se negará por HATSCHEK el intento de circunscribir el ámbito de las reglas convencionales a las relaciones entre el Parlamento y la Corona, destacando también la importancia de las reglas de los partidos (Parteisitte).

Pero es que además, se afirmará cómo en el campo del Derecho público existen normas que podríamos denominar de hecho, que representarian un estadio prejurídico, pero no por ello menos eficaces que las normas juridicas, de las que sólo se distinguirian en cuanto necesitarian ser protegidas por una verdadera norma de derecho. Tales reglas, no obstante, conducirían en cuanto necesitarían ser protegidas por una verdadera norma de derecho. Tales reglas, no obstante, conducirian siempre a una ampliación y mutación del Derecho, transformándose en derecho consuetudinario y sustituyendo al derecho legal existente. De este modo, las normas convencionales aun no siendo todavía Derecho, por carecer de la sanción de las fuentes juridicas oficiales, encontrarian su eficacia en la propia fuerza normativa de la realidad, una vez consolidadas en los reglamentos, la costumbre o la ley ${ }^{27}$.

Dicha concepción doctrinal ha sido no obstante, objeto de las siguientes críticas: en primer lugar, es discutible el criterio adoptado para la constatación de las reglas convencionales de carácter jurídico, a través de su especial reconocimiento por los reglamentos parlamentarios; en segundo lugar, seria más que dudosa, se afirmará, la pretendida creación de una categoría intermedia de normas entre las reglas puramente consuetudinarias y aquellas otras dotadas, asimismo de la nota de juridicidad ${ }^{28}$; finalmente dicha concepción, de modo semejante a la de DICEY, partiria del carácter especial de la nota de la sanción para la calificación de las normas juridicas, olvidando que no es necesario que la sanción se halle contenida preceptivamente en una norma específica, pudiendo residir tanto en los mismos engranajes del ordenamiento jurídico, como en otros supuestos de reconocimiento indirecto. Además, si la intervención de los órganos judiciales fuese siempre esencial para la determinación de la juridicidad, supondría negar el carácter de jurídico a una gran parte del Derecho internacional o dejar fuera de la garantía del Derecho una parte esencialisima del Derecho

27 Recogido por Ferracciu, ob. cit., págs. 44-47.

28 Ibidem, págs. 52-53. 
constitucional británico ${ }^{29}$. Más interesante parece, por el contrario, la posibilidad de reconocer la existencia de sanciones juridicas internas a través de asociaciones de las normas jurídicas en relación con un cierto número de convenciones ${ }^{30}$.

La tercera de las grandes aportaciones doctrinales será la de Jellinek quien partirá de unas premisas doctrinales sustancialmente diferentes a las anteriormente descritas. Para JELLINEK, dichas normas constituirian verdadero Derecho, es decir, normas jurídicas reconocidas y garantizadas por'el ejercicio de la potestad estatal. Dichas normas no serian sin embargo en la mayoría de los casos de naturaleza coactiva o imperativa, sino de carácter dispositivo.

Gracias a dicha naturaleza, las reglas convencionales podrian fácilmente adaptarse a las relaciones políticas, de por sí esencialmente mutables. Dicho Derecho dispositivo existiría en todos los países y no sólo en Gran Bretaña, de suerte que si ha quedado, no obstante, olvidado u oscurecido, se ha debido en gran parte a la incapacidad misma del Derecho público para explicarlo. Tal seria el caso, por ejemplo, de la institución del Ministerio, cuya existencia y eficacia no se halle en normas jurídicas concretas y escritas, sino en el Derecho constitucional dispositivo señalado ${ }^{31}$.

La referida argumentación doctrinal habrá sido sin embargo, objeto de las siguientes críticas: en primer término, si bien habria reconocido acertadamente el carácter convencional de los poderes atribuidos a los órganos supremos del Estado, como normas reconocidas y garantizadas por el ejercicio de las potestades estatales, prefirió negar el carácter coactivo de dichas normas, en lugar de haber señalado la naturaleza consuetudinaria de aquellas reglas convencionales que se hubiesen cumplido durante cierto periodo ininterrumpido de tiempo; en segundo lugar, se afirmará la mayor conveniencia en haber destacado la nota de necesariedad que revisten la mayoría de las relaciones que las normas convencionales regulan; finalmente, se argumentará incluso, contra la existencia de un Derecho dispositivo en el marco del Derecho público ${ }^{32}$.

Por último, y dentro de las aportaciones clásicas al tema, habría que destacar en la doctrina alemana la formulación de Radnitzky, quien a diferencia de Jellinek no verá en las convenciones constitucionales la expresión de un derecho flexible. Por el contrario, las normas convencionales constituirian un derecho absoluto, mediatamente vigente y como tal dependiente de la clausula rebus sic stantibus, dando lugar al nacimiento de

29 C. CARISTiA, «Saggio critico sul valore e l'efficacia della consuetudine nel Diritto Pubblico interno», en Scritti Giuridici Storici e Politici, T.I. Giuffré, Milán, 1953, págs. 210-211. 30 Así, Ferracciu, ob. cit., pág. 52. y ss.

${ }^{31}$ G. JeLLINEK, Verfassungsanderung und Verfassungswandlung, Berlín, 1906, págs. 27

32 Así, Ferracciu, ob. cit, págs. 53-54. 
obligaciones juridicas que tendria por objeto la fácil o automática adopción de determinadas relaciones efectivas de poder. El ejemplo más sobresaliente sería la regla convencional que impondría en los regímenes parlamentarios, la obligación por parte de los monarcas de elegir a los componentes del Ministerio de entre aquellos miembros, que gozasen de la confianza del Parlamento.

Según dicha concepción, las normas convencionales serían Derecho constitucional no escrito, pero no derecho consuetudinario; gozarian del carácter, por lo tanto, de una norma jurídica mediata, indirecta e implícitamente vigente. $Y$ todo ello, no sucederia solamente en Inglaterra, sino en otros Estados que disfrutando de un régimen parlamentario, en los que, por contra a lo que se suele pensar, la formación del derecho consuetudinario se hallaría excluida, por la brevedad manifiesta de los supuestos convencionales señalados ${ }^{33}$.

Dichas argumentaciones han sido sin embargo objeto también de las siguientes matizaciones: en primer término, se le puede reprochar la artificiosidad y excesiva sutilidad de la formulación de la pretendida clausula rebus sic stantibus, tratando de desligarse del propio derecho consuetudinario, del que al no excluir la posibilidad de su sanción y eficacia mediata, se trataria de explicar por la nota de su felxibilidad; en segundo lugar, no parecería posible acoger la tesis de un derecho mediato, pues no dejaria de ser sorprendente, se dirá, que habiendo la ley establecido los fines a satisfacer, no impusiera igualmente los medios; finalmente, no se comprendería cómo en el caso concreto del defendido fundamento del Gobierno Parlamentario, y con la utilización de idénticos medios en diferentes Estados, sin embargo, no haya dado lugar al establecimiento en todos ellos de la referida forma de gobierno ${ }^{34}$.

\section{Otras aportaciones clásicas en el Derecho constitucional británico}

Las formulaciones doctrinales posteriores a los planteamientos descritos suelen seguir sustancialmente las líneas argumentales básicas reseñadas, y especialmente la elaboración de Dicey. Así, se conceptualizan las convenciones constitucionales como las reglas de conducta relativas a la materia constitucional que son consideradas obligatorias por los diferentes órganos constitucionales, pero que no encuentran sanción en los órganos jurisdiccionales, y cuya existencia se justifica en base a la necesidad de integrar el esqueleto normativo de la Ilamada Constitución legal.

${ }^{3}$ S. RADNITZKY, «Dispositives und mittelbar geltendes Recht”, en Arch. off Rechs, 1906, págs. 380 y ss.

34 Así, Ferracciu, ob. cit., págs. 54-56. 
En la misma línea que Dicey, Mackinstosh y Wheare, partiendo de una conceptualización estrictamente imperativista y típica de los ordenamientos jurídicos anglosajones, destacarán la ausencia de enforcement judicial para justificar la falta de juridicidad de éstas ${ }^{35}$.

De modo semejante ya Jennings habria observado en primer lugar, la imposibilidad para el juez de declarar la violación de las normas convencionales, y en segundo término, la ausencia de una enunciación exterior formal, y por lo tanto, garantizadas por una menor sanctity ${ }^{36}$.

De esta forma y a diferencia de Dicey, Jennings consideraría insuficiente el criterio de la falta de apelación judicial para caracterizar al menos de forma exclusiva, la conceptualización de las normas convencionales, y ello entre otras argumentaciones, porque algunas reglas del rule of Law se hallarian del mismo modo privadas del referido enforcement reseñado. Por todo ello JENNINGS diferenciará las reglas convencionales de las normas juridicas, por las siguientes características: a) por gozar de una menor sanctity que las segundas; b) la imposibilidad de declarar su violación por parte de los órganos judiciales; c) por hallarse formuladas de un modo impreciso ${ }^{37}$.

En cualquier caso, lo que no se puede olvidar es que cuando los constitucionalistas ingleses diferencian las convenciones constitucionales de las que denominan rules of law en sentido estricto, y califican un cierto comportamiento constitucional o inconstitucional, utilizan un criterio de valoración más amplio que el de la juridicidad o anti-juridicidad, prefiriendo utilizar en muchas ocasiones los conceptos de legalidad e ilegitimidad ${ }^{38}$.

\section{Las aportaciones doctrinales más sobresalientes en el Derecho continental}

Pero no sólo en Inglaterra la doctrina se ha ocupado de caracterizar la naturaleza jurídica de las normas convencionales, sino que también en el Derecho continental se han realizado formulaciones doctrinales al respecto más o menos próximas a las elaboraciones ya señaladas, lo que ha producido que salvo peculiares construcciones, las líneas maestras de las discusiones referidas se mantienen.

35 J.P. MACKINTOSH, The British Cabinet, Stevens and sons, Londres, 1962, pág. 12, y K. WheAre, Modern Constitutions, Oxford University Press, Londres, 1964, págs. 122 y ss. De modo semejante, también se manifiesta O. Hoon PHILLIPS, The Constitutional Law of Great Britain and Commonwealth, Sweet Maxwell, Londres, 1967, pág. 25.

${ }_{36}$ I. Jennings, The Law and the Constitution, University of London Press Ltd., Londres, 1956, págs. 79 y ss.

Ibidem

38 R. Treves, // Commonwealth britannico, Giuffré, Milán, 1950, pág. 27. 
En primer lugar, se puede recoger la formulación de FERRACCIU, para quien dichas reglas convencionales derivarian esencialmente de una larga e ininterrumpida práctica fundada sobre el tácito acuerdo de los órganos supremos del Estado respecto al ejercicio de sus atribuciones y poderes. Dichas normas se hallarian mediatizadas por la necesidad de corresponder adecuadamente a las relaciones de poder de hecho, que se van desarrollando en el seno del Estado de conformidad con las nuevas exigencias sociales, y que aquéllos siguen como normas obligatorias de conducta. Se trataria, por lo tanto, de las líneas maestras y principios fundamentales de la estructura jurídico-politica de un Estado, cuyo desconocimiento daría lugar a una violación sistemática del espíritu de la Constitución, y para las que se establecería una especie de coacción jurídica indirecta (por ejemplo, y como más importante, las que establecen la forma de Gobierno parlamentario).

Frente a dichas normas a las que se les atribuye el carácter de jurídicas, se hallarían, se continúa afirmando, otras de naturaleza politica o de correttezza y cuyo respeto se hallaría subordinado al cumplimiento de ciertos condicionamientos políticos (entre los que destacarían la llamada moral de partido). Y ello, aunque si bien en teoria dicha diferencia es siempre posible aunque no se puede olvidar, sin embargo, dirá FERRACCIU, la existencia de ciertas zonas límites en las que en la práctica no resulta fácil aprehender la diferenciación realizada ${ }^{39}$.

En la misma linea de defender la juridicidad de las reglas convencionales, se manifestaría Caristia, que frente a las argumentaciones doctrinales clásicas señaladas que quieren privar de juridicidad a dichas normas, defenderá su carácter jurídico. Así, criticará las posiciones doctrinales que prescriben como necesario que las posibles sanciones jurídicas se hallen recogidas en concretas y específicas normas, o la intervención de los órganos judiciales para calificar de juridicas ciertas reglas.

Frente a tales construcciones, se argumentará, que si las referidas convenciones constitucionales son efectivamente observadas como estrictamente obligatorias por los órganos estatales y gozan de una semejante obligatoriedad que garantice su cumplimiento, poco o nada ha de importar que una cierta norma especifique, sancione o deje de sancionar sus inobservancias $^{40}$.

39 Ferracciu, ob. cit., págs. 58-62.

40 Caristia, ob. cit., págs. 202-212. Como ejemplo típico de norma convencional, el autor señala la instauración del Gobierno Parlamentario en Italia durante la vigencia del Estatuto Albertino. Afirmará, que negar a las convenciones el carácter de normas jurídicas, supondría, por lo tanto, admitir por ejemplo, que en Italia bajo la vigencia de dicho texto constitucional, la Monarquía parlamentaria no constituia una forma jurídica, sino una simple variedad política adoptada entre la Corona y el Parlamento. 
Desde argumentaciones parecidas se'manifestará MICELI, quien después de rechazar el criterio señalado del enforcement ante los órganos judiciales para atribuir o no juridicidad a las diferentes normas, afirmaría el carácter jurídico de las normas convencionales derivado no solamente como algunos pretenderían, de los mismos principios generales del derecho, sino de un convencimiento jurídico específico, que determinaría su respeto $^{41}$.

Tampoco admitiría en las normas convencionales REPOSO, la ausencia de un control judicial para despojar a aquéllas del carácter de juridicidad. Así, y en primer lugar, porque habria una gran parte de normas seguramente jurídicas a nivel constitucional y que no serían accionables ante los tribunales y órganos de justicia; en segundo término, porque incluso en los paises que gozasen de un control de constitucionalidad de las leyes, dichas fuentes vendrían caracterizadas por una valoración de las reglas de autonomia de los sujetos titulares del poder sancionador, cuyo ejercicio se hallaría condicionado por la particular estructura y modalidad de las funciones que desarrollan; finalmente, y aun en el supuesto de que se pudieran reconocer, sería difícil de juridificar por los órganos jurisdiccionales la dimensión objetiva y los límites dentro de los cuales las reglas constitucionales han de mantenerlas y reconocerlas ${ }^{42}$.

Reconocerá también carácter jurídico a las normas convencionales, MORTATI quien después de afirmar que no se puede considerar a la costumbre como el único medio de mutaciones constitucionales, defenderá la naturaleza juridica de dichas normas una vez desechado el señalado criterio de la justiciabilidad como definidor de las verdaderas reglas jurídicas. A diferencia de las costumbres constitucionales, las convenciones se hallarían acompañadas de la ya mencionada claúsula rebus sic stantibus, lo que permitiría su no aplicación cuando las circunstancias de hecho hayan podido variar, cuando la regla convencional inicialmente establecida haya perdido su naturaleza y modo de $\operatorname{ser}^{43}$.

Desde posiciones semejantes se manifestarán, CRISAFULLI quien ve en las convenciones constitucioales la expresión de un derecho de naturaleza dispositiva o como el reflejo de la mencionada claúsula rebus sic stantibus, que perdería su eficacia una vez que han mudado las circunstancias de hecho que acompañaron su nacimiento y establecimiento, o ESPÓSITO, quien delimitará restrictivamente la figura de las convenciones a las decisiones concordadas y admitidas cerca de las instituciones consti-

${ }^{41}$ V. MiCELI, Principii di Diritto costituzionale, Societá Editrice Libraria, 2." ed., Milán, 1913, pág. 76.

${ }_{42}$ A. REPoso, «Le reg̀ola di correttezza costituzionale nel sistema delle fonti-fatto», en Scritti in onore de C. Mortati, T. I, Giuffré, Milán, 1977, págs. 269-270.

43 C. Mortatı, Istituzioni di Diritto Pubblico, T.I, Cedam, 9." ed., Padua-Milán, 1975. págs. 316-317 y “Costituzione”, en Enciclopedia del Diritto, T. XI, Giuffré, Milán, 1962, págs. 202-203. 
tucionales en el ejercicio concreto y práctico del desarrollo constitucional ${ }^{44}$.

Sin embargo, no toda la doctrina constitucional tiende a reconocer la juridicidad de las normas convencionales, y así, frente a los planteamientos doctrinales referidos, se ha mantenido y se continúa manteniendo la ausencia de carácter juridico en aquéllas.

Se debe precisar, no obstante, desde un primer momento, que la pretendida caracterización de las convenciones como normas desprovistas de juridicidad, no supone necesariamente reconducir dichas reglas al campo de la mera moralidad o ética, o desprovistas de toda obligatoriedad de trascendencia exterior o social. $Y$ ello, porque aun negándoles el carácter de normas jurídicas no tienen por qué necesariamente quedar relegadas a un papel secundario respecto de las reglas dotadas de juridicidad, tanto en los supuestos ordinarios de cumplimiento y acatamiento, como en los de violación e infracción.

Dentro de la tendencia doctrinal manifestada, habría que señalar a S. ROMANO, para quien las llamadas convenciones constituirian una especie de moral o moralidad constitucional, si bien no todas ellas producirian una «idéntica responsabilidad» en los supuestos de quiebra o incumplimiento. Así, habria que diferenciar las que darían lugar a un serio y verdadero quebranto del orden e, incluso, de la misma noción de paz pública, de las que sólo causarian la represión y la impopularidad por quien las infringe ${ }^{45}$.

Sugerente será también la construcción de GUARINO, quien parte de la acertada constatación de que las diferentes normas jurídicas no se hallan en el mundo de las distintas realidades sociales de un modo aislado, sino en relación con otras normas. Las reglas jurídicas no actuarían, por lo tanto, en coordinación con todas las demás, de manera que los institutos o sistemas jurídicos no serían el fruto de simples procesos de abstracción, sino que, por el contrario, responderian a realidades y supuestos bien delimitados y concretos. Actuarían de esta manera, como el enlace de las diferentes normas que se podrían reconducir a un único principio o principios colegiados o entrelazados, y que dependerian, caso por caso, según la diferente naturaleza de las relaciones de que se trate, del ambiente donde deben de operar y de las diferentes normas ya emanadas. POSITO.

44 CrisafulLi, ob. cit., pág. 154, quien recogerá además la opinión al respecto de Es-

¿5 S. Romano, “Diritto e correttezza costituzionale» en Scritti Minore, T.I, Giuffré, Milán, 1950, pág. 275. Entre los ejemplos que se citan, se podrian destacar los siguientes: durante el Estatuto Albertino el rey debía consentir una Ley votada por las dos Cámaras del Parlamento; en el Derecho inglés, la Cámara de los Lores no debe de ejercitar la iniciativa en materia financiera; la obligación en los gobiernos parlamentarios, de los Ministros de dimitir cuando han perdido la confianza del Parlamento; así también, y en el sistema británico en los supuestos de discrepancia entre la Cámara Baja y la Cámara Alta, esta última ha de ceder a los dictados de la Cámara de los Comunes. 
Pues bien, dichos principios que se prolongan en zonas aparentemente extrañas al Derecho, pero de una importancia no necesariamente inferior a las materias reguladas por él, aparecerían como el presupuesto del reconocimiento de las denominadas convenciones constitucionales. Convenciones constitucionales que serian un fenómeno típicamente constitucional, y que se caracterizarian por las siguientes notas: en primer lugar, y de modo semejante a la costumbre, por la ausencia de formulación expresa; en segundo término, por no ser manifestación de una fuente de derecho en sentido estricto. Su fuerza social, dice GUARINO, no reposaría en la respectiva fuerza de los diferentes órganos y sujetos políticos; asi, sólo tendrían "vida" cuando las fuerzas políticas y sociales perduren, pero con la peculiaridad de que su autoridad social no se sostiene por la particularidad de su origen, sino solamente por su contenido; finalmente, dichas normas se hallarian en buena parte desprovistas de una sanción preventivamente descrita y regulada, provocando su violación ciertamente una reacción, pero dependiendo ésta sustancialmente de las relaciones entre los órganos que les dan vida. De este modo, si bien desde un punto de vista estrictamente jurídico no comportaría en ellas, ni un vicio del posible acto infractor, ni una aplicación de sanciones jurídicas, sustrayéndose además a todo juicio de legitimidad, no se podría olvidar sin embargo, como la violación de las referidas normas convencionales provoca siempre una violación o fractura más o menos amplia del sistema entendido en su totalidad ${ }^{46}$.

Menos afortunada nos parece, en cambio, la formulación de TREVES, quien negando a las convenciones constitucionales el carácter de normas jurídicas, afirmará que aunque se quisiese negar que la denominada opinio iuris sea un elemento esencial de la costumbre, no se podría, sin embargo, dejar de reconocer que la creencia contraria al establecimiento de la norma pueda dar lugar al nacimiento de una regla jurídica. Por ello, la ausencia del referido requisito tendría un valor esencial en la ausencia del carácter jurídico de las convenciones constitucionales ${ }^{47}$.

De esta forma, y evitando la cristalización de las reglas convencionales en perfectas normas jurídicas, se lograria una mayor flexibilidad y acomodación de dichas normas a las nuevas necesidades y exigencias políticas, lo que no supone, no obstante, desconocer la indiscutible conexión entre convención y derecho, pues aquellas que surgen próximas a aquél lo presuponen, facilitan su aplicación y precisan la extensión de las normas jurídicas, pudiendo incluso convertirse en tales ${ }^{48}$.

46 G. Guarino, «ll Presidente della Repubblica Italiana» en Rivista Trimestrale di Diritto Pubblico, n. 4, Milán, 1951, págs. 969-977.

${ }_{47}$ TreVes, ob. cit., pág. 525.

48 lbidem, pág. 526. 
No obstante, la aportación doctrinal más significativa en contra del carácter jurídico de las normas convencionales, al menos en el reciente Derecho italiano, es la de RESCIGNO, quien si bien se ocupa detenidamente de aquéllas, sin embargo, les niega dicho carácter en base a semejantes formulaciones a las ya recogidas dentro de la más estricta doctrina imperativista británica.

En esta línea, las normas convencionales serian reglas, que como ya hemos destacado, disciplinan las relaciones entre los diferentes sujetos políticos soberanos. Se trataría de reglas que presuponen comunmente la existencia de normas de carácter jurídico, es decir, de aquellas normas que individualizan la autoridad soberana y gozan de los efectivos requisitos de la validez juridica. Son, por lo tanto, aquellas reglas que nacen cuando siendo permanentes los mínimos indispensables fijados por las normas juridicas, las referidas autoridades soberanas fijan en sus posteriores relaciones recíprocas, reglas de comportamiento debidas, que en gran parte suplirían las lagunas del ordenamiento jurídico ( $y$, por lo tanto, podrán ser codificadas y devenir juridicas), o en parte quedan confiadas a la misma autonomía de los respectivos sujetos políticos (estas últimas, carecerían de dicha juridicidad) ${ }^{49}$.

Las normas convencionales serian, dice RESCIGNO, reglas creadas y establecidas mediante acuerdo por los diferentes sujetos politicos, mutables libremente por ellos, e, incluso, por uno solo de los sujetos señalados, simepre que dispusiera de la fuerza política necesaria. La consecuencia de todo ello no sería sino la ausencia de coercibilidad por parte de los órganos judiciales y tribunales, o de modo general por una autoridad diferente y externa a los propios sujetos interesados ${ }^{50}$.

Y ello sería de tal forma, se continua diciendo, porque las reglas convencionales regulan relaciones politicas, traduciendo los equilibrios necesarios de los distintos sujetos políticos en sus diferentes relaciones recíprocas. De este modo, cualquier órgano judicial que pretendiese mantenerlas y exigirlas con la fuerza, debería de gozar él mismo del propio carácter de los sujetos políticos a los que trata de imponer su decisión, e incluso disfrutando lógicamente de más fuerza que aquellos para poder imponer su criterio o arbitraje. La consecuencia entonces no sería otra que la de haber dado lugar a una nueva regla convencional como sujeto partícipe de un nuevo equilibrio político ${ }^{51}$.

Resumiendo, para RESCIGNO, las reglas convencionales vendrian caracterizadas por las siguientes notas:

49 Rescigno, ob. cit., págs. 15-18.

so Ibidem, p.122. Coincide con la tesis ya formulada de Romano, que negaba a las reglas convencionales la nota de juridicidad, pero que por el contrario, admitia la posibilidad de que fuesen sancionadas.

${ }^{51}$ Ibidem, pág. 124. 
a) Vienen establecidas de modo informal, en el sentido de no ser presicritas de alguna forma especial ${ }^{52}$.

b) No son recabadas de ningún texto escrito, lo que no quiere decir, que no puedan ser redactadas por escrito ${ }^{53}$.

c) Pueden encontrar su origen, a diferencia de la costumbre, en un solo precedente ${ }^{54}$.

d) Soportan una serie interminada de excepciones, de puntuales o reglas especiales para los supuestos particulares ${ }^{55}$.

e) Se trata de reglas creadas por pocos sujetos que pueden, no obstante, ser modificadas unilateralmente por un sujeto político que' pudiera imponer su propia voluntad a los otros ${ }^{56}$.

f) Las razones determinantes del nacimiento y modificación de las normas convencionales se encuentran en razones políticas impuestas por las relaciones entre los sujetos interesados ${ }^{57}$.

g) Se trata de reglas no coercibles ${ }^{58}$.

h) Son reglas que carecen de la nota de juricidad, aunque los órganos judiciales deben de tenerlas en cuenta, cada vez que les sea necesario para sentenciar y enjuiciar ${ }^{59}$.

i) Presuponen un cierto contexto legal dentro del cual encuadrarse ${ }^{60}$.

Finalmente, y en primer término, se dirá, mientras que algunas de las convenciones no se podrian transformar en reglas generales, otras, por el contrario, sí pueden transformarse en costumbres juridicas o mudar el contenido de los actos normativos generales ${ }^{61}$; en segundo lugar, y mien-

52 lbidem, pág. 109.

s3 lbidem, págs. 109 y 116.

54 lbidem, pág. 117.

55 Ibidem, pág. 110.

Ibidem, pág. 125.

lbidem, pág. 118.

lbidem, pág. 122

Ibidem, págs. 122 y 142.

lbidem, págs. 23-24.

lbidem, pág. 138. 
tras algunas reglas convencionales son más estables y duraderas que las propias normas jurídicas, otras por el contrario, suelen modificarse sencillamente con la mutación de las concretas relaciones politicas ${ }^{62}$.

De modo semejante, se manifiesta también en la doctrina italiana LAVAGNA, quien después de recoger las formulaciones tanto en contra o a favor de la naturaleza jurídica de las normas convencionales, se decide por negarles el carácter de fuentes jurídicas a no ser que su observancia prolongada y el elemento de la opinio iuris, acaben convirtiéndolas en verdaderas y propias reglas consuetudinarias ${ }^{63}$.

Sin embargo, entre los dos grandes planteamientos doctrinales, bien a favor o en contra del carácter jurídico de las normas convencionales, se ha desarrollado asimismo por la doctrina ciertas formulaciones que vendrian, en cierto modo, a matizar las argumentaciones más básicas y sobresalientes reseñadas.

Asi, en la doctrina italiana, algunos les atribuirán el carácter de juridicidad si bien dentro de una conceptualización formalista, al considerarlas como "normas de utilización de los poderes legales" ${ }^{64}$; en otras ocasiones, si bien se les negaría la nota de la juridicidad, se afirmará, sin embargo, cómo en ocasiones se podrían asimilar a las verdaderas normas juridicas ${ }^{65}$; para otros, carecerían de valor juridico por sí mismas, si bien el reenvio o referencia a la propia Constitución les podria atribuir en cierto modo, el carácter reseñado ${ }^{66}$; en otras formulaciones, se hacen subordinar las posibles manifestaciones juridicas de las reglas convencionales, del reconocimiento que éstas pueden disfrutar por parte de la comunidad ${ }^{67}$; finalmente, y conforme a una observación particularizada de las diferentes reglas que se presentan como convencionales, se diferenciarán dos hipótesis bien distintas: de un lado, aquellas normas que se hallarian asistidas por la convicción de la oportunidad de su aplicación, y que gozarían del respeto y observancia por parte de sujetos que no habian participado en

62 Ibidem, pág. 124; ver también del mismo autor el Corso di Diritto Pubblico, Zanichelli, Bolonia, 1980 , págs. 422 y ss.

63 C. Lavagna, Istituzioni di Diritto Pubblico, , U.T.E.T. 5. ed., Turín, 1982, pág. 222.

aA Así, Rossetto, recogido por Elvira Perales, ob. cit., pág. 129. 169-170.

G5 Galladore Palleri, Diritto Costituzionale, Giuffre, 10." ed., Milán, 1972, págs.

66 A. TESAURo, "Le consuetudine costituzionale e la norma de correttezza», en Scritti Giuridici in memoria de V.E. Orlando, , Vol. II, Cedam, Padua, 1957, pág. 506, quien diferenciará dos supuestos distintos: de una parte, cuando se presentan como imprescindibles para garantizar el respeto de la Constitución de acuerdo con su propia razón fundamental de ser o de actuar, como sucede cuando se trata de evitar que se produzca un atentado al propio texto constitucional; de otra parte, cuando las propias normas del Derecho constitucional hayan de encontrar su ejecución «en base a una valoración discrecional que impone a los diversos órganos el conformarse según la orientación colectiva que encontraria su más destacada manifestación en las normas de cortesia».

${ }_{67}$ R. ORestano, «Dietro la Consuetudine», en Rivista Trimestrale di Diritto Pubblico, número 3, Milán, 1963, pág. 530. 
el reconocimiento y formación de aquéllas; de otro, las que se presentarian como simples normas de corrección constitucional, y de cuya inobservancia si bien se producirian consecuencias en el plano de las relaciones sociales, no podrian ser consideradas, no obstante, como actos contrarios al derecho ${ }^{68}$.

Por lo que respecta a las aportaciones de la doctrina austríaca y alemana, KELSEN caracterizaría de modo general a las normas convencionales, como de reglas que pertenecerian a la esfera de las relaciones prejurídicas, es decir, a la esfera de las normas meramente sociales. Dichas reglas podrian transformarse en derecho a través de su establecimiento como costumbres, pero hasta entonces permanecerian en un estadio prejurídico, y por lo tanto, explicable desde el punto de vista sociológico de la ciencia del ser, pero no desde la perspectiva de las normas jurídicas o del deber ser.

A diferencia de HATSCHEK, que diferenciaba las reglas convencionales de las normas jurídicas, por contener éstas últimas prescripciones para el futuro, mientras que aquéllas gozarían de un valor de justificación a posteriori por acciones políticamente oportunas, KELSEN señalaría que también las normas convencionales ya formadas fijarian prescripciones para el futuro, y que por tanto, las normas jurídicas constituirian una justificación para el pasado ${ }^{69}$.

En la misma linea, SCHEUNER después de constatar cómo en los regímenes parlamentarios son escasas las normas jurídicas, negará que las reglas convencionales puedan gozar del carácter de la juridicidad, denominándolas normas colectivas, al derivar su sanción de no haber seguido las pautas y conductas marcadas por la comunidad social ${ }^{70}$.

De manera semejante se manifestaba así mismo KRIELE, quien las caracteriza de normas básicas de la moralidad política y social, pero no

68 Asi, A. Pizzorusso, Fonti del Diritto, Zanichelli, Bolonia y Del Foro Italiano, Roma, 1977, págs. 550 y ss. Tal seria el caso de los acuerdos expresos o tácitos entre el Estado y las diferentes regiones, sobre todo en los primeros tiempos de la consolidación del régimen de las regiones de estatuto ordinario. De igual modo, se afirma las relaciones entre el Estado y los sindicatos.

Recoge, asi mismo, la distinción apuntada por Rescigno, para quien, mientras que las costumbres serian heterónomas por razón de los sujetos, al ser el producto de un fenómeno colectivo del que participan todos los miembros o al menos un número indeterminado de ellos, las convenciones por el contrario, serian expresión de la autonomía de los sujetos, al surgir de las concretas relaciones entre ciertos sujetos titulares de oficios públicos (en contra de dicha opinión, ver por ejemplo, G. ZAGREBELSKY, Sulla consuetudine nella teoria delle fonti del Diritto, UTET, Turín, 1970, pág. 202, nota 4).

69 H. KeLSEN, Teoría General del Derecho y del Estado, Trad. Eduardo García Maynez, Universidad Nacional Autónoma de México, 2. ${ }^{a}$ reimp., México, 1979, pág. 151.

70 Citado por C. GIROLA, «Le consuetudini costituzionali», en Studi Urbaniti, n. 3 y 4 , 1931, pág. 84 , nota 21. 
del mundo del Derecho ${ }^{71}$. Finalmente, y mientras se ha destacado la dificultad de conceptualizar y determinar el carácter de las reglas convencionales, problemática que podría abarcar el campo de la sociología, de la ética, de las más graves relaciones de poder, de la interpretación, de la misma revisión constitucional e incluso del llamado Derecho natural ${ }^{72}$, KRUGER las equipara a los Ilamados usos del Derecho privado (Sitte) ${ }^{73}$.

En la doctrina francesa, los planteamientos doctrinales girarán en los mismos términos básicamente, que las aportaciones del Derecho constitucional italiano señaladas. Así, mientras que para algunos como M. HAURIOU, y aun no siendo coercibles por los órganos jurisdiccionales, revestirian, sin embargo, el carácter de reglas jurídicas siendo sancionadas por la opinión pública ${ }^{74}$, para otros como $A Z Q U I N{ }^{75}$, o más recientemente CHEVALIER $^{76}$, se trataría por el contrario, de normas o prácticas de carácter político, pero no de verdaderas reglas juridicas.

Posición doctrinal peculiar será la mantenida en la doctrina portuguesa por GOMES CANOTILHO, que después de calificarlas como fuentes extraordinem, añadirá que no crean originariamente normas jurídicas, lo que hace pensar, que en determinados supuestos si pudieran adquirir dicho valor ${ }^{77}$.

En la práctica sin embargo, y como dirá JEANNEAU, «ante la fuerza o la importancia de ciertas prácticas politicas, el problema del valor jurídico en materia constitucional resulta sumamente académico" ${ }^{78}$.

\section{Posición que se defiende}

De la expresión doctrinal reseñada, la primera de las puntualizaciones en parte ya esbozada, y que se nos antoja como necesaria, es la im-

7 M. KRIELE, Introducción a la Teoría del Estado, T.E. Bulgyin, Depalma, Buenos Aires, 1980, pág. 270.

72 Así, H. Hüber, recogido por Elvira Perales, ob. cit., pág.

73 H. Kruger, Allgemeine Staatslehre, 1966, págs. 488 y ss.

${ }^{74}$ M. Hauriou, Précis de Droit Constitutionnel, Sirey 3." ed., París, 1933, pág. 221.

75 B. Azouin, «La désuétude en Droit constitutionnel», en Revue de Droit Public et de ia Science Politique, T. XLV, n. 4, Paris, 1928, págs. 712-714, donde se recoge la doctrina clásica inglesa más sobresaliente al respecto.

76 J. CheVAlLIER, "La coutume et le Droit constitutionnel français", en Revue du Droit Public et de la Science Politique, n. 6, París, 1970, págs. 1408-1409; también, y entre otros, J. LAFERRIERE, "La coutume constitutionnelle, son role et sa valeur en France», en Revue du Droit Public et de la Science Politique, n. 1, Paris, 1944, pág. 30; recientemente, por ejemplo, Ch. Debbasch, J. Bourdon, J.M. Pontier, J.C. Riccl, Droit Constitutionnel et Institutions Politiques, Ed. Economica, París, 1983, pág. 74, donde se recoge, asimismo, parte de la doctrina británica sobre el tema. 687.

7 J. Gomes Canotilno, Direito costitutional, Almedina, 3.ed., Coimbra, 1983, págs. 686pág. 58.

B. Jeanneau, Drọit constitutionnel et Institutions politiques, Dalloz, 3. ed., Paris, 1972, 
posibilidad en buena y estricta técnica jurídica de extrapolar el concepto de las convenciones constitucionales $-y$ en última instancia del propio concepto de lo jurídico- del Derecho constitucional británico a los países pertenecientes al Derecho o sistema continental.

No parece aceptable la conceptualización de las reglas convencionales como si de simples prácticas o máximas de moral constitucional o política se tratase, y de su negación de todo valor jurídico strictu sensu por no ser susceptibles de recibir las correspondientes sanciones judiciales en los supuestos de su violación o quebrantamiento, pretendiendo hallar su obligatoriedad en la misma fuerza de la ley o derecho legislado, que indirectamente resultaría igualmente infringido.

No nos parece convincente erradicar del mundo del Derecho, en principio, tal categoría de reglas -algunas de ellas esencialísimas y básicas para la propia configuración jurídico política del régimen británico-, por el simple hecho de no poder ser accionadas ante los tribunales y órganos jurisdiccionales. Dicho planteamiento no sería sino consecuencia de una visión del derecho imperativista y típica del mundo anglosajón, en el que el enforcement judicial se defiende como elemento básico y esencial en la caracterización de las normas como jurídicas.

Fácilmente, se podría observar la falacia de dichos presupuestos, si los tratásemos de llevar hasta sus últimas consecuencias, pues si ello fuese cierto, muchas de las normas jurídicas establecidas en los textos constitucionales, así como en los ordenamientos jurídicos que carecen de un órgano de justicia constitucional, quedarian absurdamente fuera del mundo del Derecho. Lo cierto, por el contrario, es que nos movemos dentro del campo de las relaciones juridicas, por lo menos algunas de ellas, no siendo equiparable el concepto de justiciabilidad con el de juridicidad.

Tampoco parece convincente negar a las convenciones constitucionales eficacia normativa, como veremos más adelante, por lo menos a aquellas que son el resultado de una larga práctica que se ha institucionalizado, y se ha aceptado por los órganos básicos del sistema jurídico politico, y que gozan asimismo del consentimiento de la propia comunidad. Si los ingleses en estos supuestos, no hablan de legal custom sino de convention, se debe exclusivamente a la ficción de considerar como costumbres jurídicas solamente a aquellas que se habian fijado antes del año 1189 , año del inicio del reinado de Ricardo I. Dicha fundamentación puede ser aceptada por los juristas británicos, pero no dejará de ser, al menos fuera del ordenamiento jurídico inglés, contingente y ajena, lógicamente, a la propia estructura de las normas juridicas.

Además, dicho principio careceria de aplicación en el campo de las relaciones constitucionales a diferencia de las costumbres del Derecho privado, en las que no pudiéndose probar el tiempo en que aquéllas se habían establecido, se exigiría su prueba inmemorial. Y ello porque en el Derecho constitucional las referidas costumbres si pueden ser ordinariamente fijadas en un determinado periodo de tiempo más o menos preciso. 
En tercer lugar, y como acertadamente se ha señalado en la doctrina española por GARCIA PELAYO, las convenciones constitucionales gozan de un valor jurídico muy variable, "pues en unos casos son meras normalidades, mientras que en otros están dotadas de fuerte pretensión normativa " ${ }^{79}$, o lo que es lo mismo, habría que diferenciar las normas que establecen y prescriben determinados modelos o pautas de conducta, de las reglas que no superan el campo de las meras pretensiones de cortesía.

Asi, en el primero de los casos, no cabría duda que siendo dichas normas elaboradas y respetadas por los órganos superiores y primarios del sistema jurídico constitucional, darían lugar a un Derecho constitucional no escrito, que no habria que confundir necesariamente con el derecho consuetudinario.

Dichas normas convencionales serian por lo tanto, normas jurídicas, y ello se ha señalado, pensamos que acertadamente, por una doble razón: de una parte, porque serian esenciales a la propia configuración de la organización y estructura constitucional inglesa; de otra, porque gozarían de exigibilidad, que se concretaría en su respeto y exigencia por los diferentes órganos y sujetos políticos ${ }^{80}$, caracterizados por las notas de primariedad y superioridad.

De importancia, en cambio, secundaria se nos antojan otras matizaciones que se podrían realizar a la teoria tradicional británica de las convenciones constitucionales: en primer término, que no todas las reglas convencionales hallan una sanción indirecta en el derecho legislado; en segundo término, la existencia en el ordenamiento jurídico británico de normas jurídicas que no son fijadas ni sancionadas por los órganos judiciales, por las autoridades administrativas ${ }^{\mathrm{B} 1}$.

Pero el problema en lo que a nosotros respecta, no se limitaría al carácter jurídico o meramente político de las normas convencionales, sino a la posibilidad de recoger dicha clase de normas en los países de Derecho continental, y en particular como pueden ser los casos de Italia y España, en ordenamientos que gozan de una Constitución escrita y rigida.

La interrupción de la evolución constitucional entre nosotros después de la Guerra Civil, y a diferencia del Derecho constitucional italiano que, por lo menos formalmente se prorrogaría incluso durante los años del fascismo hasta el texto constitucional de 1947, hace dificil poder sustentar

79 Garcia Pelayo, ob. cit., pág. 354.

Ibidem, pág. 288.

- Ibidem, donde, además se señala haciendo suya la argumentación de Jennings, de como los tribunales no ponen en vigor la ley (enforced), sino que lo único que hacen es declarar que puede ser ejecutada contra infractores individuales; de otro lado, habria algunas convenciones que con el transcurso del tiempo han nulificado de un modo completo ciertas normas del derecho escrito. 
dicha categoria, al menos con la santidad e institucionalización que algunos han defendido en ciertos países como es el caso italiano.

Sin embargo y como punto de partida, incluso desde el país vecino se ha señalado la dificultad, amén de la complicación de la extrapolàción de las reglas convencionales británicas a ordenamientos jurídicos como los reseñados, y especialmente a aquellos que encontrarían su origen en un solo precedente.

Entre las razones que se habrian argumentado resaltarian las siguientes: en primer lugar, el hecho de que a diferencia de la Constitución británica, en los supuestos referidos existirian textos constitucionàles escritos, lo que sustraería en principio un gran campo al ámbito de desarrollo de las reglas convencionales; en segundo lugar, la inexistencia de una opinión pública tan consolidada como la británica, o lo que es $10 \mathrm{mismo}$, no existirian los valores suficientes que pudieran dar lugar de forma pacífica a las necesarias e imprescindibles good reasons del Derecho constitucional británico; en tercer lugar, la existencia de unos sistemas de partidos multipartidistas harían nulo o al menos poco eficaz el interés por observar las posiciones adquiridas ${ }^{82}$; en cuarto lugar, la existencia en muchos casos de un órgano encargado de conocer sobre la constitucionalidad de las leyes; en quinto lugar, tanto la Constitución italiana como española son más detalladas, concretas y pormenorizadas que el texto constitucional norteamericano, y qué decir de la Constitución británica; finalmente, en los sistemas jurídicos como el nuestro no existiría tampoco el culto y reverencia al precedente, característico de los países del common law ${ }^{83}$

Pero es que, además, tampoco las características ni la misma obediencia a las normas convencionales es la misma en el Derecho constitucional británico que cuando de dicha categoria se habla por parte de ciertos sectores de la doctrina continental, y en especial italiana, que és la que se ha ocupado más pormenorizadamente del tema y de la problemática apuntada.

Tal sería por ejemplo, el caso de RESCIGNO, que afirmará respecto a la categoría de las normas convencionales en el Derecho constitucional continental, y en especial en el Derecho italiano, tanto la admisibilidad de que puedan ser violadas, como su inesenciabilidad respecto a la conservación del mismo sistema político de que se trate ${ }^{84}$.

Como se puede ver fácilmente, dicha construcción no sólo se hallaria muy lejana, sino que de igual modo contradeciría el mismo concepto de

B2 Asi se manifiesta, Zagrebelsky, ob. cit., págs. 198-199. Recoge como ejemplo de regla convencional en el sentido anglosajón del término, la señalada instauración de la forma de gobierno parlamentario en Italia durante la vigencia del Estatuto Albertino.

83 Asi también, TReves, “Convenzioni...», ob. cit., págs. 526 y ss.

34 G. Rescigno, La responsabilitá politica, Giuffré Milán, 1967, págs. 7 y ss. 
las normas convencionales que vimos defendia la misma doctrina clásica británica, que atribuía a las conventions of the constitution los caracteres de máxima obligatoriedad y esencialidad en la supervivencia del propio sistema político-constitucional. $Y$ ello es asi porque en el Derecho constitucional británico se piensa que hay ciertos principios tan esenciales para la propia existencia de la organización constitucional y sobre los que existe tal elevado grado de consenso, que haría, desde la perspectiva jurídica inglesa, innecesaria y vana su protección a través del clásico enforcement judicial $^{85}$.

Por ello, en Inglaterra no se puede defender, desde la posición doctrinal de corte imperativista mantenida, que los principios e instituciones básicas del sistema constitucional se hallen, como puede suceder en los paises de Derecho continental, por verdaderas y propias normas juridicas. Asi, bastaría recordar cómo, de acuerdo con DICEY, la obediencia a las convenciones constitucionales se fundamentaría de los siguientes modos: en primer término, por el deseo de conservar las antiguas y establecidas tradiciones del gobierno constitucional; en segundo término, con el objetivo de mantener y conservar el orden fijado en el propio aparato estatal, procurando que los diferentes órganos políticos se adecuen a lo preceptuado en la Constitución, y que desplieguen las funciones que tienen encomendadas de forma coordinada alcanzando la deseada fluidez de la normativa constitucional; finalmente, con el deseo de conservar la confianza del propio pueblo, y consecuentemente de mantenerse en el poder político ${ }^{86}$.

Lógicamente, y como ya tuvimos ocasión de apuntar, no todas las convenciones gozarian de la misma fuerza, ni supondrian las mismas consecuencias en los supuestos de violación y quebranto. Así, se distinguirá en primer lugar, entre las reglas convencionales que se referirian a determinados círculos restringidos -afectarian sólo a los propios sujetos que las viven-y aquellas otras que incidirian más allá del ámbito en el que son estrictamente ejecutadas, y que pueden dar lugar a la quiebra de otras normas susceptibles de ser garantizadas por los propios órganos judiciales, asi como de provocar una cierta respuesta por parte de los otros sujetos y órganos constitucionales, y de forma especial por el Parlamento. Finalmente, existirian ciertas normas convencionales que por su trascendencia e importancia van acompañadas en el caso de su infracción o incumplimiento por una sanción de la propia opinión pública.

Lo reseñado, no quiere decir no obstante, que no puedan existir en el ejercicio de los poderes discrecionales atribuidos en los textos constitucionales a los órganos políticos en los países de Derecho continental, ciertos acuerdos expresos o tácitos, de manera semejante a lo que suce-

85 Así, ZagrebelSKY, ob. cit., págs. 202-203.

DiCEY, ob. cit., págs. 442 y ss. 
dería en Gran Bretaña, aunque eso sí, con las puntualizaciones hasta ahora descritas.

\section{ALGUNOS EJEMPLOS DE CONVENCIONES CONSTITUCIONALES EN EL DERECHO CONTINENTAL COMO INSTRUMENTO DE MODIFICACIONES CONSTITUCIONALES}

En el Derecho comparado es la obra de Rescigno la que de forma más detallada y pormenorizada se ha ocupado de estudiar y clasificar los diferentes tipos de normas convencionales en el Derecho constitucional continental, y en especial italiano.

Al ocuparnos de estudiar la fundamentación y naturaleza de las reglas convencionales, ya criticamos la formulación imperativista del constitucionalista italiano, remitiéndonos, pues, a lo ya expuesto. Sin embargo, y por lo que respecta a la esquematización de posibles ejemplos de normas convencionales, aun haciendo la salvedad de que quizás muchas de ellas fuesen en realidad supuestos perfectos de verdaderas costumbres constitucionales, la aportación de RESCIGNO se nos antoja como la más completa y didáctica de las realizadas por los estudiosos de la materia en el país vecino.

Parte RESCIGNO de la clasificación de las reglas convencionales en cuatro grandes categorias:

1) Aquellas reglas que sustituirian a lo preceptuado por las reglas legales existentes, de modo que si bien continuarian siendo respetadas en la forma, sin embargo, la regulación sustancial será la disciplinada desde entonces por las propias normas convencionales.

Este tipo de convenciones respondería al esquema clásico de las normas convencionales británicas. Así, por ejemplo, y según la constitución británica la disolución de la Cámara de los Comunes correspondería a la Reina, y sin embargo, por una convención actualmente vigente, en la práctica es competencia exclusiva del primer ministro; lo mismo se podría decir del poder del monarca de sancionar las leyes, que desde el siglo XVIII, y gracias a lo preceptuado convencionalmente ha configurado y transformado dicha facultad en un deber.

En Italia y a pesar de que la aceptación de dichas normas convencionales podría producir en parte una violación de la propia Constitución de 1947, que se halla protegida por un procedimiento específico de reforma constitucional (art. 138), en la práctica, no obstante, se habrian desarrollado e institucionalizado algunos supuestos. 
Así, la Constitución italiana señala que el presidente del Consejo propondrá a los ministros (art. 92), cuando en la práctica los ministros vienen propuestos por los partidos que integran las coaliciones de las diferentes fuerzas politicas; también el artículo 89 de la Constitución, que exigiendo que todo acto del presidente de la República para ser válido ha de estar refrendado por los propios ministros que lo propongan, en la práctica no siempre se cumple; de suerte contraria es la evolución sufrida por el artículo 79 del texto constitucional, que al establecer como competencias del presidente de la República la amnistía y el indulto por ley de delegación de las Cámaras, en la práctica ha reducido, no obstante, el papel de aquél a una función meramente formal y honorífica; en el ámbito parlamentario el artículo 64, que establece que cada Cámara adopte el propio Reglamento por mayoría absoluta o la necesidad de la presencia de la mayoría de los miembros, cuando en la práctica las modificaciones parciales del Reglamento se producen por mayoría simple de sus miembros a menos que el presidente de un grupo parlamentario o diez diputados exigieran la mayoria cualificada. Respecto a la necesidad de la presencia de los miembros, ésta se presume, salvo prueba en contrario.

Se incluyen, además, como ejemplos convencionales, las reuniones o acuerdos informales entre representantes de los partidos de la mayoría, los acuerdos entre el Gobierno y los Sindicatos, los comités de ministros o el nombramiento de los ministros y la formulación del programa de Gobierno, aspectos todos ellos en los que de un modo u otro despliegan su eficacia las reglas convencionales ${ }^{87}$.

2) Dichas reglas convencionales se producen cuando las propias reglas constitucionales dejan abierta la puerta a una posible pluralidad de reglas ulteriores de comportamiento, que vendrian asi, a complementar la normativa constitucional.

Asi, por ejemplo, la Constitución italiana señala en su artículo 92 que el presidente de la República nombra al presidente del Consejo y a los ministros. Sin embargo, el propio texto constitucional no concreta cómo el presidente de la República deberia de proceder a dichos nombramientos, dejando la interpretación y desarrollo del precepto constitucional a su regulación por las normas convencionales.

También en cuanto a las consultas se podrían, quizás señalar las reglas siguientes: 1) El presidente de la República debe ordinariamente proceder a la realización de ciertas consultas. 2) No está determinado ni el orden ni el número de consultas a realizar. 3) Mientras algunos sujetos deben ser siempre consultados (representantes de los partidos políticos),

37 Rescigno, «Le convenzioni...», ob. cit., págs. 27 y ss.; “Corso...», ob. cit., págs. 424425, y en el artículo "Le convenzioni della Costituzione», en Studi in Memoria de Carlo Esposito, Vol. III, Cedam, Padua, 1973, págs. 2078-2082. 
otros lo son más que otra cosa por razones de cortesia (ex-presidentes de la República, ex-presidente de la Asamblea Constituyente, presidentes de la Cámara y el Senado, ex presidentes del Consejo. 4) El Jefe del Estado se debe de abstener de consultar a otros sujetos que no sean los establecidos por la práctica, y especialmente, cuando dichas innovaciones podrian sospechar razones de parcialidad política. 5) Es irrelevante el orden de las consultas. 6) En general, y antes de proceder al nombramiento, las consultas no deben ser repetidas. 7) En algunas ocasiones después de las consultas, se ha producido una especie de prenombramiento, y 8) si el nombrado renunciara, se abre un nuevo período de consultas.

Por lo que respecta al nombramiento y mientras que en líneas generales, tanto la forma como la sustancia no han institucionalizado ninguna regla de conducta inflexible, la problemática se concretaría en saber si el Jefe del Estado podria condicionar el nombramiento a la aceptación de un programa político, de una fórmula de Gobierno o interferir el nombramiento de los ministros, aspectos estos últimos sobre los que la respuesta debe ser negativa.

Otros ejemplos, serían los que se refieren al refrendo de los actos del presidente de la República por parte de los ministros, al ejercicio del derecho de disolución de las Cámaras por el Jefe del Estado, la suplencia del presidente de la República o las relaciones entre el presidente del Consejo y los ministros, a la vista del artículo 95 de la Constitución italiana, supuestos todos ellos completados por lo preceptuado en diferentes normas convencionales ${ }^{88}$.

3) Se trata de aquellas reglas independientes y autónomas que no constituyen a diferencia de las anteriores, concretas especificaciones o desarrollo de lo preceptuado por las reglas jurídicas constitucionales. Dichas reglas convencionales presuponen ciertamente la existencia de un sujeto politico-constitucional y el conjunto de sus respectivos poderes y facultades, pero sin enlazarse con ninguna norma específica.

Como ejemplo de este tipo de normas, la regla convencional que impediria como línea de principio que el presidente de la República no pueda criticar públicamente al Parlamento o al Gobierno sobre cuestiones políticas, y menos aún a un partido político concreto o a un parlamentario; de forma inversa, el Parlamento no podrá tampoco criticar al presidente de la República.

Estas dos reglas generales podrian, sin embargo, desglosarse en varias hipótesis: a) el Parlamento no puede realizar críticas al presidente de la República; b) el Gobierno no puede criticar al Jefe del Estado; c) el presidente de la República no puede criticar al Gobierno; d) el Gobierno

38 Rescigno, “Le convenzioni...», ob. cit., págs. 45 y ss.; “Corso...», ob. cit., pág. 425; Le convenzioni della...” ob. cit., págs. 2082-2087. 
no puede criticar al Parlamento; e) el Jefe del Estado podría criticar al Parlamento por razones de incumplimiento de los preceptos constitucionales, pero no por motivos políticos; $f$ ) el presidente de la República no puede criticar a los grupos parlamentarios o a los parlamentarios singularmente considerados; $g$ ) el Tribunal Constitucional puede criticar al Gobierno y al Parlamento por infracción o violación constitucional, pero no por razones políticas y $h$ ) los parlamentarios deben abstenerse de criticar al Jefe del Estado.

Reglas convencionales se han desarrollado consecuentemente, en otros aspectos de la vida política y parlamentaria italiana como pueden ser: la cuestión de confianza, la responsabilidad solidaria del Gobierno, sobre la dimisión del Gobierno después de la celebración de las elecciones políticas generales, la dimisión del Gobierno después de la elección de un nuevo presidente de la República (en el Estatuto Albertino se producía después de la subida al trono de un nuevo monarca), la concreta realización del principio de confianza entre el Gobierno y el Jefe del Estado (sustancialmente diferente, a lo establecido por el Estatuto Albertino) y la irresponsabilidad politica del presidente de la República (consecuencia de la regla, según la cual «el Jefe del Estado debe de actuar de modo que no se haga merecedor de recibir criticas") ${ }^{89}$.

4) Aquellas que consisten en la sustitución de un significado político típico de un acto juridico, que continuaría produciendo sus resultados jurídicos originarios, al margen de los nuevos efectos.

Tal seria, por ejemplo, el caso del voto negativo de una Cámara sobre un proyecto de ley presentado por el Gobierno. Jurídicamente y de modo estricto, no supone más que la decadencia de la proposición legal gubernamental, pero en la práctica y vida política los partidos políticos y el propio Gobierno le podrian atribuir otra consecuencia política. A saber, la desconfianza de la Cámara respecto al Ejecutivo.

De modo particular se podrían también recoger en el Derecho constitucional italiano, los siguientes supuestos: la denegación de la Ley de Presupuestos, el rechazo de la Cámara a convalidar un decreto-ley o la constitución de una comisión de investigación. De manera generalizada, determinados aspectos de la función de l'indirizzo político, las convenciones al principio de responsabilidad política como relación constitucional

89 Rescigno, «Le convenzioni costituzionali» ob. cit., págs. 70 y ss.; “Corso...”, ob. cit., págs. 425-426; «Le convenzioni della...», págs. 2087-2088. 
entre el Gobierno y el Parlamento o la atribución de ciertos efectos políticos a las propias elecciones ${ }^{90}$.

Desde un planteamiento sustancialmente diferente, enmarcado en la más clásica tradición jurídica británica, WHEARE ha subrayado las diferentes formas en que tanto el uso como la convención pueden desplegar su actividad frente a lo preceptuado en los textos constitucionales. Si bien la mayoría de los supuestos recogidos, se hallarian más cercanos de las costumbres constitucionales que de las reglas convencionales, sin embargo, a nivel esquematizador y descriptivo, la aportación señalada no deja de ser apreciable.

La primera de las posibilidades en las que las convenciones desplegarían sus efectos, sería en la anulación de una determinada prescripción de la Constitución: "... la convención penaliza el brazo de la ley. Insistamos en que no se trata de enmendar o abolir la ley. No amputa el brazo, sólo impide que se use ${ }^{91}$. Así, la facultad del Jefe del Estado de establecer el veto a las leyes aprobadas por el Parlamento es sin embargo abolido convencionalmente, tal y como sucede en países como Dinamarca, Noruega, Suecia, Holanda o Bélgica; en la misma línea, se pueden recoger algunas constituciones de los miembros de la Commonwealth que concedian a los gobernadores generales la facultad de negar su asentimiento a las leyes, o la abolición del derecho de disolución de la Cámara Baja por el Jefe del Estado durante la vigencia de la III República en Francia; finalmente, el anterior establecimiento tanto en Estados Unidos como en Francia de una regla convencional contraria a la reelección para un tercer o segundo mandato presidencial respectivamente, al margen de las excepciones de Roosevelt y Lebrun ${ }^{92}$.

En segundo lugar, aquellos casos en los que si bien los diferentes poderes reconocidos constitucionalmente gozan de efectiva vigencia, sin

"o Rescigno, "Le convenzioni costituzionali», ob. cit., págs. 96-108; “Corso...”, ob. cit., pág. 426 y "Le convenzioni della...", ob. cit., págs. 2088-2090. El autor diferenciará además entre «reglas necesariamente jurídicas» (así, la lugartenencia y los adecretos durante el estado de asedio" en el Estatuto Albertino; en el régimen Republicano, los reglamentos ministeriales, los límites posteriores que el Parlamento establece en los supuestos de delegación legislativa, el nombramiento del vicepresidente del Consejo de Ministros o de los ministros sin cartera), "reglas necesariamente convencionales" y «reglas convencionales por oportunidad política".

Otros ejemplos de normas convencionales necesarias, aunque desde perspectiva doctrinal diferente, en GuARino, ob. cit., págs. 973 y ss., donde se recogen algunas normas convencionales desplegadas en la actividad desarrollada por el Presidente de la República.

Curiosas son asimismo las reflexiones de P. BISCARETTI DI RUFFIA, "La Revisione Costituzionale negli 'Stati Socialisti' Europei: 'Norme giuridiche' e 'norme convenzionale'», en Rivista Trimestrale di Diritto Pubblico, n. 2, Roma, 1981, págs. 427 y ss., sobre la existencia de ciertas reglas convencionales en las denominadas democracias populares y en concreto, en referencia a los procedimientos de revisión constitucional.

91 WHEARE, ob. cit., pág. 129.

${ }^{2}$ Ibidem, págs. 129-132. 
embargo no son en la práctica ejercidos por los órganos a los que originariamente se atribuyen, sino por otros sujetos diferentes. Una primera manifestación de dicho supuesto, se hallaría en la forma de nombrar los ministros en aquellos países que disfrutan de forma de gobierno de Gabinete, en los que el Jefe del Estado -Inglaterra, Canadá, Australia, Nueva Zelanda, Africa del Sur, Monarquías escandinavas, Holanda y Bélgicadesigna a las personas que el primer ministro le propone; asimismo, el traspaso de otros poderes de manos del Jefe del Estado a otros órganos, en asuntos como el de la disolución del Parlamento, la práctica de los poderes ejecutivos, o los poderes para declarar la guerra o dirigir las relaciones exteriores; finalmente, en cuanto al procedimiento de elección del presidente y vicepresidente de los Estados Unidos, que en la práctica ha variado sustancialmente desde la originaria atribución a los colegios electorales ${ }^{93}$.

Finalmente, aquellos supuestos en que el uso y las convenciones completan lo establecido en las propias Cartas Constitucionales. Tal sería el caso de los reglamentos internos de las Cámaras, que por ejemplo durante la III y la IV República francesa fijó el sistema de comisiones parlamentarias; o bien, el cuidado del presidente de los Estados Unidos de nombrar a los miembros del Gabinete de entre las principales regiones del pais; en Australia y Canadá, donde se pretende, que cada uno de sus Estados debe de gozar de cierta representación en el Gabinete de la Commonwealth, - la representación de ciudadanos de habla francesa o inglesa en el Gabinete de Canadá y la representación en el de Quebec, respectivamente (de la misma manera, Quebec y Ontario han de tener parecida representación legal); la diferencia de situación y funciones de los presidentes de la Cámara de los Representantes norteamericana y el speaker británico (organizador de programa de su propio partido el primero, y, tradicionalmente, imparcial el segundo); la composición del Consejo Federal en Suiza donde se respeta que tanto Berna, Zurich y Vaud se hallen siempre representados en aquél, como que solamente cinco de los siete miembros que lo componen sean elegidos entre los cantones de lengua alemana, etc...94.

93 Ibidem, ob. cit., págs. 132-135.

94 Ibidem, págs. 135-140. Recoge también la posibilidad de transformación de dichas reglas convencionales en derecho legislado, supuesto este que se produciria por diversas razones: en primer lugar, porque se considera que la ley posee mayor sanción que la convención; en segundo lugar, porque al ser discutida se considera oportuno definir la problemática estableciendo su consolidación en la norma legal; finalmente, por ser obstruida por la convención, requiriendo para poder ser efectiva la modificación de aquella.

Por lo que se refiere a a las diferencias entre ley y convención, ser recoge además el clásico planteamiento de Jennings, quien establecía al respecto las siguientes: a) en caso de incumplimiento de la ley se podrá acudir ante los tribunales, a diferencia de las convenciones que carecerian de dicha posibilidad; $b$ ) las leyes son establecidas por los órganos legislativos competentes; $y, c)$ la mayor santidad de las leyes. 